\title{
Growth Kinetics of Probiotic Lactobacillus Strains in the Alternative, Cost-Efficient Semi-Solid Fermentation Medium
}

\author{
Katarzyna Śliżewska *(1) and Agnieszka Chlebicz-Wójcik *(i) \\ Institute of Fermentation Technology and Microbiology, Faculty of Biotechnology and Food Sciences, \\ Lodz University of Technology, Wólczańska 171/173, 90-924 Łódź, Poland \\ * Correspondence: katarzyna.slizewska@p.lodz.pl (K.Ś.); agnieszka.chlebicz-wojcik@dokt.p.lodz.pl (A.C.-W.); \\ Tel.: +48-42-6313-481 (K.Ś. \& A.C.-W.)
}

Received: 23 October 2020; Accepted: 24 November 2020; Published: 27 November 2020

check for updates

\begin{abstract}
Simple Summary: Commercial microbiological media are often expensive because of used ingredients; therefore, their application in high-density cell production is cost-consuming. Since Lactobacillus bacteria are commonly used in various industries, and especially as probiotics, alternative cheaper media are needed. Additionally, the approach is to use food or agriculture by-products, which can support the growth of bacteria due to their components. Among them, cereals and flours are used worldwide; therefore, their usage as a medium for Lactobacillus spp. can be accessible, easy, and affordable. Results obtained from the following study showed that a mixture of wheat, barley, maize, and rye flours combined with distilled water is a good medium for the efficient growth of selected probiotic Lactobacillus spp.
\end{abstract}

\begin{abstract}
The growing need for Lactobacillus bacteria usage in industry and the expending probiotic market led to a search for new cost-efficient fermentation media from which a high yield of these bacteria could be obtained. The following study aimed to elaborate cultivation medium, for Lactobacillus spp. growth, which main components would be wheat, maize, barley, and rye flours. The optimal temperature for Lactobacillus growth in new semi-solid fermentation (SSF) medium, water content, and $\mathrm{pH}$ of the medium were analyzed by the plate count method. It was established, that the highest bacteria counts were obtained from cultures conducted in the SSF medium with flours to water ratio of 1:1.5 with a natural $\mathrm{pH}$ of 6.0 at $37^{\circ} \mathrm{C}$. Subsequently, the growth kinetics of analyzed strains, in both MRS and the SSF media, were studied. The newly designed media contributed to the increased duration of selected Lactobacillus strains lag phase, which varied from 1.98 to 5.64; nevertheless, the maximum growth rate of the strains was two times higher in the SSF medium rather than in MRS, which also resulted in shorter generation time. The developed medium has the potential to become a new cost-efficient fermentation medium for Lactobacillus spp.
\end{abstract}

Keywords: Lactobacillus; cultivation; flours

\section{Introduction}

Species belonging to Lactobacillus genera are ones of the most wildly used probiotics in animal feeding, which are defined as live microorganisms conferring health benefits to a host when administrated in the proper dosage [1,2]. Probiotics are proved to have an advantageous effect on people suffering from gastrointestinal system disorders, such as infectious diarrhea, inflammatory bowel diseases, celiac disease, and food allergies among many others [3]. What is more, Cicero et al. (2020) recently described the positive effect of Lactobacillus spp. probiotic strains, in the presence of 
inulin and fructooligosaccharides, on elderly patients, whose cardiovascular and insulin resistance risk factors, related to metabolic syndrome, were decreased [4]. Moreover, these beneficial microorganisms are used as an alternative for antibiotic growth promoters (AGPs), which were prohibited in European Union (EU) in 2006, which caused an increase in the infection rate among livestock [2]. The probiotic market is foreseen to bring 74 billion USD income in 2024, which is over two times higher than in 2015 (35 billion USD) [5].

The growing need for Lactobacillus spp. usage in the industry resulted in the necessity of obtaining a high density of these bacteria at low cultivation costs [6,7]. Lactobacillus spp. are characterized by high nutritional requirements, due to their weak ability to synthesize amino acids and vitamins from B-group [8]. Therefore, their cultivation needs to be conducted in a rich medium, which includes fermentable carbohydrates, nucleic and amino acids, B-complex vitamins, as well as different minerals [9]. Moreover, Lactobacillus spp. bacteria primarily use peptides in order to fulfill their demand for nitrogen [10]. For LAB cultivation purpose, on a laboratory scale, meat or yeast extract are commonly used as a nitrogen source; however, these components contribute to the high cost of ordinarily used de Man, Rogosa, and Sharpe medium (MRS) [11]. Low-cost medium alternatives are looked for mainly among food and agriculture by-products and wastes [10]. Cereals such as wheat, barley, maize, or rye, which are commonly used for animal feed, are proven to be a good source of nutrients for many LAB species $[9,12]$.

Besides medium composition, Lactobacillus spp. growth can be influenced by a set of various conditions such as temperature, $\mathrm{pH}$, oxygen concentration, or water activity $[13,14]$. The optimum temperature and $\mathrm{pH}$ conditions for lactobacilli growth are $30-40{ }^{\circ} \mathrm{C}$ and $5.5-6.2$, respectively; however, the Lactobacillus genus is diversified and belonging bacteria can grow in temperature ranging from 2 to $53{ }^{\circ} \mathrm{C}$ and $\mathrm{pH}$ varying between 4.5 and 6.5, some strains can grow in even lower $\mathrm{pH}$ [15]. Culture conditions as well as fermentation medium composition, in which Lactobacillus spp. bacteria are grown, can influence growth kinetics parameters such as specific growth rate and lag phase duration, which is the time in which bacteria adapted to new media and do not proliferate [16-18].

The study aimed to develop a new cost-efficient medium based on commercially available agriculture products used in monogastric animals feeding, such as cereals-derived flours, for Lactobacillus spp. cultivation. The scope of the research consisted of the determination of optimal growth conditions, namely, water content and $\mathrm{pH}$ of the designed medium as well as temperature. Moreover, the growth kinetics in both MRS and newly elaborated medium were estimated and compared.

\section{Materials and Methods}

\subsection{Strains}

Subjects of the research were Lactobacillus strains with documented probiotic properties, namely $L b$. paracasei ŁOCK 1091, Lb. pentosus ŁOCK 1094, Lb. plantarum ŁOCK 0860, Lb. reuteri ŁOCK 1092 and Lb. rhamnosus ŁOCK 1087 [19-24]. For the strains isolation from alternative sources, viz the gastrointestinal tract (GIT) of monogastric animals, such as broiler chickens and pigs, as well as plant silage, the Rogosa agar (BD Difco ${ }^{\mathrm{TM}}$, Sparks, NV, USA) was used. The Lactobacillus strains were deposited in the Lodz Collection of Pure Cultures (ŁOCK 105) of the Institute of Fermentation Technology and Microbiology (Lodz University of Technology; Lodz, Poland) and their beneficial impact on monogastric animals were previously analyzed [25-27].

For the storage purposes of Lactobacillus spp. the Cryobanks ${ }^{\mathrm{TM}}$ (Copan Diagnostics Inc., Murrieta, CA, USA) were used, which were kept at $-22^{\circ} \mathrm{C}$.

\subsection{Inoculum Preparation}

The strains were activated and then passaged twice in de Man, Rogosa, and Sharpe broth (MRS, $\mathrm{pH}=6.2 \pm 0.2$; Merck Millipore, Burlington, MA, USA). The incubation of the strains was conducted at $37^{\circ} \mathrm{C}$ for $24 \mathrm{~h}$. Subsequently, the strains were centrifuged at $10,732 \times g$ relative centrifugal 
force (RCF) for 10 min (Centrifuge MPW-352; MPW, Warsaw, Poland). The obtained biomass of each strain was washed with $0.1 \mathrm{M}$ phosphate-buffered saline (PBS; Calbiochem ${ }^{\circledR}$, Merck Millipore, Burlington, MA, USA) by centrifuging. Afterward, the cells were resuspended in the PBS and optical density (OD) was adjusted to correspond to $10^{7}$ colony-forming units per milliliter (CFU/mL) cell density at $600 \mathrm{~nm}$ wavelength (Beckman DU 640, Beckman Coulter Inc., West Sacramento, CA, USA).

\subsection{Semi-Solid Fermentation Medium Design}

Based on the natural flours commonly used in livestock feeding, such as wheat $(40 \% w / w$; Młyny Szczepanki Sp. z o.o., Łasin, Poland), barley (30\% w/w; Młyn Oliwski, Gdańsk, Poland), maize (20\% w/w; RADIX-BIS Sp. z o.o., Rotmanka, Poland) and rye (10\% w/w; Polskie Młyny S.A., Warsaw, Poland) flours, the semi-solid fermentation (SSF) medium was designed $(\mathrm{pH}=6.0 \pm 0.2)$. The medium composition was determined on the basis of the literature review. Flours nutritional values, declared by producers, are presented in Table 1.

Table 1. Nutritional values of used flours (information obtained from the package of each product).

\begin{tabular}{cccccc}
\hline \multirow{2}{*}{ Type of Flour } & Energy & Carbohydrates & Total Lipids & Protein & Dietary Fibre \\
\cline { 2 - 6 } & {$[\mathbf{k c a l} / \mathbf{1 0 0} \mathbf{g}]$} & 73.0 & 1.6 & 11.0 & NA $^{1}$ \\
\hline Wheat & 350 & 71.2 & 4.0 & 11.9 & NA \\
Barley & 376 & 70.5 & 3.0 & 5.6 & 7.5 \\
Maize & 337 & 74.0 & 2.2 & 8.1 & 13.0 \\
Rye & 301 & ${ }^{1}$ not available.
\end{tabular}

Distilled water was added to the flours mixture in three different ratios, namely 1:1, 1:1.5, and 1:2. Subsequently, the SSF media were sterilized by autoclaving and inoculated with the Lactobacillus strains separately. After $24 \mathrm{~h}$ of incubation at $37^{\circ} \mathrm{C}, 1 \mathrm{~g}$ of sample was suspended in $10 \mathrm{~mL}$ sterile saline solution, homogenized, and serial decimal dilutions were prepared. The bacteria number was determined by the plate count method with the use of MRS agar. Each experiment was conducted in three replication and the bacterial count was given as CFU per gram (CFU/g). Moreover, viable cells productivity (VCP) was calculated (1) according to Ming et al. (2016) with modifications [28]:

$$
V C P=\frac{X}{t}
$$

where $X$ stands for total viable cell count $(\mathrm{CFU} / \mathrm{kg})$, whereas $t$ is the total fermentation time $(\mathrm{h})$.

\subsection{The Effect of Temperature and $p H$ on the Growth of Lactobacillus pp. Strains}

Each strain's inoculum was introduced into tubes with MRS broth or SSF medium with standardized $\mathrm{pH}$ of $6.2 \pm 0.2$, as well as with modified initial $\mathrm{pH}$ set at 4.0, 4.5, 5.0, 5.5, 6.0, and 6.5. To establish the temperature impact on the strains' growth, the tubes with inoculated media with standard $\mathrm{pH}$ were incubated at $4,20,30,37,44$, and $55^{\circ} \mathrm{C}$ for $24 \mathrm{~h}$. The $\mathrm{pH}$ level effect on the growth of the strains was determined after cultivation at $37^{\circ} \mathrm{C}$ for $24 \mathrm{~h}$.

After the incubation process, serial decimal dilutions were prepared and the number of cells was detected by the plate count method with the usage of MRS agar. Before dilution, $1 \mathrm{~g}$ of each sample obtained from the SSF medium was suspended in sterile saline solution $(10 \mathrm{~mL})$ and homogenized. Next, plates were incubated at $37^{\circ} \mathrm{C}$ for $48 \mathrm{~h}$ and, subsequently, the bacterial count was given as $\mathrm{CFU} / \mathrm{g}$ or $\mathrm{CFU} / \mathrm{mL}$. Each parameter for all the strains was tested in three replications.

\subsection{Growth Kinetics of the Lactobacillus Strains in the Semi-Solid Fermentation Medium}

The probiotic strains were cultivated in the SSF medium, and MRS broth comparatively, for $30 \mathrm{~h}$ in the temperature and $\mathrm{pH}$ conditions adjusted accordingly to the obtained data from point 2.4. The 
number of bacteria was established analogous as in point 2.4, at the time of inoculation and after 4, 8 , $12,16,24$, and $30 \mathrm{~h}$ of incubation. Moreover, the $\mathrm{pH}$ of the culture media was measured at the same time points. The assay was performed in triplicate.

Estimation of the growth curve was performed with the Gompertz model in the Origin 6.1 software (OriginLab Corp., Northampton, MA, USA). DMFit version 3.5 (ComBase, https://www.combase.cc/), which is an Excel add-in, was used to establish maximum growth rate ( $\mu$ max) and duration of lag phase $(\lambda)$, as well as, to calculate a generation time (GT) for every strain cultivated in each medium.

\subsection{Statistical Analysis}

Statistical analysis was performed with XLSTAT software (Addinsoft, SARL, Paris, France). The data showed herein constitute the arithmetic means of values from three repetitions. One-way analysis of variances (ANOVA), at a significance level of $p<0.05$, was performed for outcomes obtained from growth performance assay in SSF media with different water contents, as well as for VCP results. Significantly different mean values were marked with various lowercase letters $(a-c)$. Before performing ANOVA, data were checked for normal distribution (Shapiro-Wilk test) and homogeneity of variances (Bartlett's test). Moreover, Tukey's post hoc test was used after each ANOVA.

Furthermore, heatmaps were used to present outcomes gathered from growth performance assay in SSF medium in various temperature and $\mathrm{pH}$ conditions. Plots were prepared with the usage of the ClustVis web tool (https://biit.cs.ut.ee/clustvis/), data were not scaled or transformed. Additionally, the hierarchical clustering analysis (HCA), based on Euclidean distance and average linkage, was applied.

\section{Results}

\subsection{Effect of the Water Content in Semi-Solid Fermentation Medium on the Growth of Lactobacillus Strains}

The highest growth of selected Lactobacillus spp. was observed when bacteria were cultivated in the SSF medium with flours to water ratio of 1:1.5. The number of Lactobacillus spp. varied between 8.86 and $10.15 \log (\mathrm{CFU} / \mathrm{g})$. Except for $\mathrm{Lb}$. paracasei ŁOCK 1091 strain, the higher water content in the SSF medium resulted in significantly weaker growth and the average number of bacteria was $9.28 \log (\mathrm{CFU} / \mathrm{g})$. The lowest bacteria count was obtained when strains were cultivated in a medium with flours to water ratio of 1:1.0. The results are presented in Figure 1.

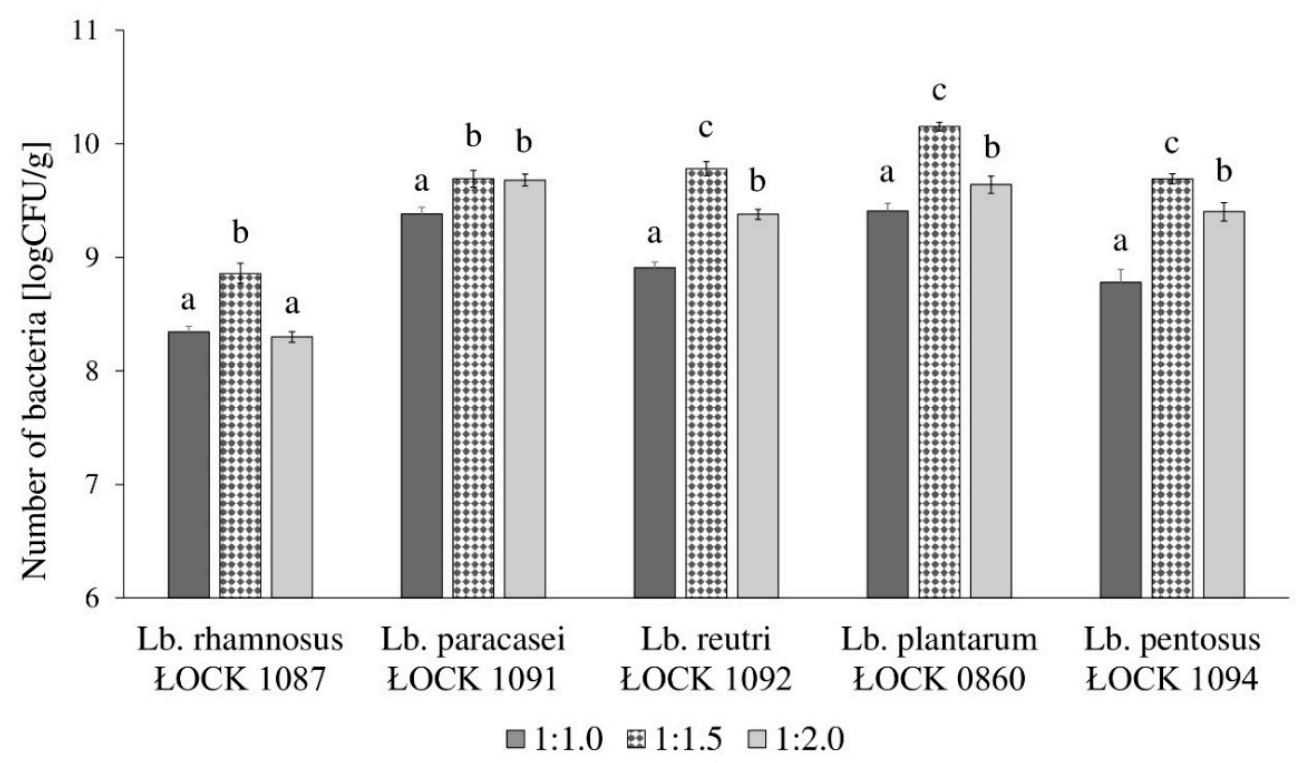

Figure 1. Growth performance of five Lactobacillus spp. (abbreviated as Lb.) in the semi-solid fermentation (SSF) medium, with three different water contents, in which the ratio of flours to water was 
as follows: 1:1.0, 1:1.5, and 1:2.0. ŁOCK is a designation of strains obtained from the Lodz Collection of Pure Cultures (Institute of Fermentation Technology and Microbiology, Lodz University of Technology; Lodz, Poland). Moreover, different lowercase letters (a-c) stands for significantly various mean values of bacterial growth per one strain according to performed one-way ANOVA with post hoc Tukey's test $(p>0.05)$.

The VCP was contingent on the water content in the newly designed SSF medium (Table 2). An increase of flours to water ratio, from 1:1.0 to 1:1.5, resulted in up to 7.5 times higher VCP. Nonetheless, a further increase in water content (ratio: 1:2.0) in the SSF medium diminished the VCP, which varied from $9.44 \times 10^{9}$ to $1.85 \times 10^{11} \mathrm{CFU} /(\mathrm{kg} \times \mathrm{h})$. This indicates a decrease in the productivity of between 2.68 and $69.11 \%$ when compared to the same parameter obtained in the medium with flours to water ratio of 1:1.5. However, the VCP in SSF medium with flours to water ratio 1:2.0 was up to almost 4 times higher than in the same medium with water content equal to the amount of the flours (ratio: $1: 1.0)$.

Table 2. Viable cells productivity of selected Lactobacillus strains cultivated in SSF mediums with different water contents.

\begin{tabular}{|c|c|c|c|}
\hline \multirow{3}{*}{ Lactobacillus Strain } & \multicolumn{3}{|c|}{ Flours to Water Ratios } \\
\hline & 1:1.0 & 1:1.5 & $1: 2.0$ \\
\hline & \multicolumn{3}{|c|}{$\mathrm{VCP}\left[\times 10^{9} \mathrm{CFU} /(\mathrm{kg} \times \mathrm{h})\right] \pm \mathrm{SD}^{1,2,3}$} \\
\hline rhamnosus ŁOCK $1087^{4}$ & $9.27 \pm 1.23^{a, 5}$ & $30.56 \pm 6.36^{b}$ & $9.44 \pm 2.66^{\mathrm{a}}$ \\
\hline paracasei ŁOCK 1091 & $102.08 \pm 13.66^{\mathrm{a}}$ & $206.94 \pm 36.22^{b}$ & $201.39 \pm 24.85^{b}$ \\
\hline reuteri ŁOCK 1092 & $34.72 \pm 3.18^{\mathrm{a}}$ & $254.86 \pm 37.81^{c}$ & $100.69 \pm 10.28^{b}$ \\
\hline plantarum ŁOCK 0860 & $108.33 \pm 16.54^{\mathrm{a}}$ & $597.22 \pm 55.68^{c}$ & $185.42 \pm 29.39^{b}$ \\
\hline pentosus ŁOCK 1094 & $27.78 \pm 2.41^{\mathrm{a}}$ & $209.72 \pm 16.84^{c}$ & $106.94 \pm 20.32^{b}$ \\
\hline
\end{tabular}

${ }^{1} \mathrm{VCP}$ stands for viable cells productivity; ${ }^{2} \mathrm{CFU}$ is an abbreviation of colony-forming units; ${ }^{3} \mathrm{SD}$ corresponds to a standard deviation; ${ }^{4}$ ŁOCK is a designation of strains obtained from the Lodz Collection of Pure Cultures (Institute of Fermentation Technology and Microbiology, Lodz University of Technology; Lodz, Poland); ${ }^{5}$ Various lowercase letters $(\mathrm{a}-\mathrm{c})$ represent significantly different mean values of VCP per one strain according to performed one-way ANOVA with post hoc Tukey's test $(p>0.05)$.

\subsection{Temperature and $p H$ Levels Impact the Growth of the Selected Lactobacillus Strains}

Selected Lactobacillus strains showed the ability to adapt and grow in a wide spectrum of temperatures and under varied $\mathrm{pH}$ conditions (Figure 2). Based on the horizontal dendrograms presented in Figure 2, the highest count of bacteria, regardless of used media, was observed when cultures were conducted at $37^{\circ} \mathrm{C}$ and the initial $\mathrm{pH}$ of the medium was varying from 5.0 to 6.0. Nevertheless, the substation of MRS with the SSF medium resulted in enhanced growth of $L b$. plantarum ŁOCK 0860 and Lb. pentosus ŁOCK 1094 at $30^{\circ} \mathrm{C}$. Furthermore, the heatmap shows that the highest number of Lactobacillus spp. was obtained in the SSF medium with an initial pH set at 6.0. On the other hand, the initial $\mathrm{pH}$ of MRS that resulted in the highest yield of cells was strain-dependent and varied from 5.5 to 6.5. The optimal growth conditions $\left(37^{\circ} \mathrm{C}, \mathrm{pH}=6.0\right)$ resulted in a better proliferation of Lactobacillus strains in the SSF medium than in MRS, which is shown by vertical dendrogram indicates (Figure 2). 


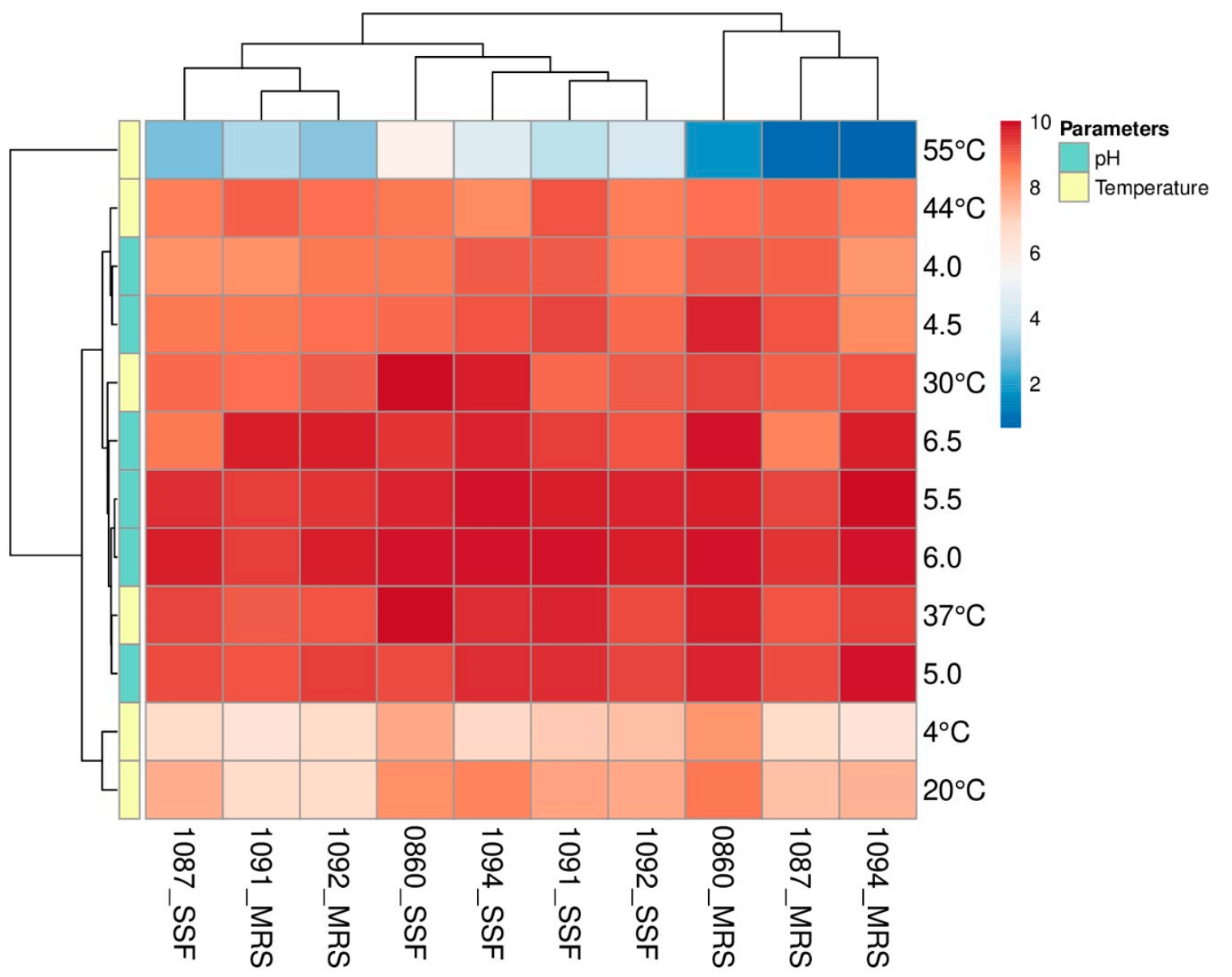

Figure 2. A heatmap presents the growth of analyzed Lactobacillus spp. (rhamnosus ŁOCK 1087, paracase $i$ ŁOCK 1091, reuteri ŁOCK 1092, plantarum ŁOCK 0860 and pentosus ŁOCK 1094) which were cultivated in de Man, Rogosa, and Sharpe (MRS) broth or the semi-solid fermentation (SSF) medium, with standardized $\mathrm{pH}$, in diverse temperatures, or various $\mathrm{pH}$ levels of media in $37^{\circ} \mathrm{C}$. The obtained numbers of bacteria are displayed as the logarithm of colony-forming units per milliliter $\log (\mathrm{CFU} / \mathrm{mL})$ (MRS medium) or gram $\log (\mathrm{CFU} / \mathrm{g}$ ) (SSF medium). Strains are listed at the bottom of the heatmap as the ŁOCK collection numbers with the medium in which they were cultivated, whereas modified growth parameters are given on the right side of the plot.

\subsection{The Growth Kinetics of the Lactobacillus Strains in the Semi-Solid Fermentation Medium}

Higher numbers of cells were reached when each of the analyzed probiotic strains was cultivated in the SSF medium rather than in commercially available MRS (Figure 3). After $30 \mathrm{~h}$ of incubation, cell density obtained from Lactobacillus spp. cultures conducted in MRS varied between $8.85 \pm 0.19$ and $9.68 \pm 0.08 \log (\mathrm{CFU} / \mathrm{mL})$, whereas when probiotic monocultures were grown in the SSF it was higher by up to 1.5 decimal logarithmic unit (the average of $10.28 \log (\mathrm{CFU} / \mathrm{g})$ ). On the other hand, pH level decreased more substantially in MRS than in the SSF medium, reaching value ranging from $3.94 \pm 0.15$ to $4.18 \pm 0.19$ and from $4.54 \pm 0.32$ to $4.84 \pm 0.17$, respectively, subsequently to $30 \mathrm{~h}$ of cultivation (Figure 3). 


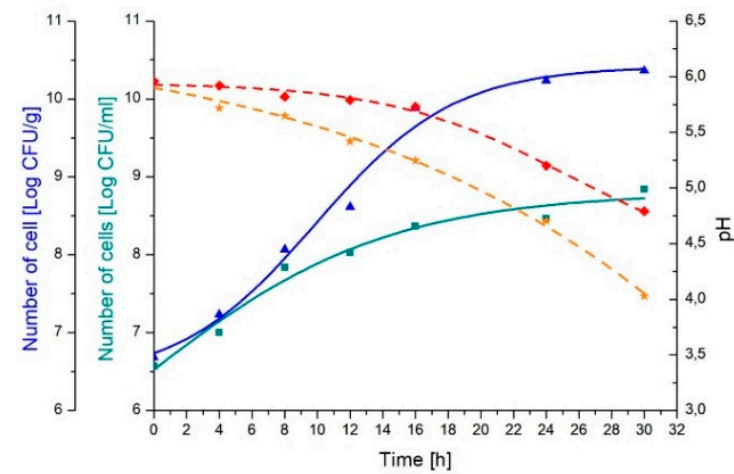

(a)

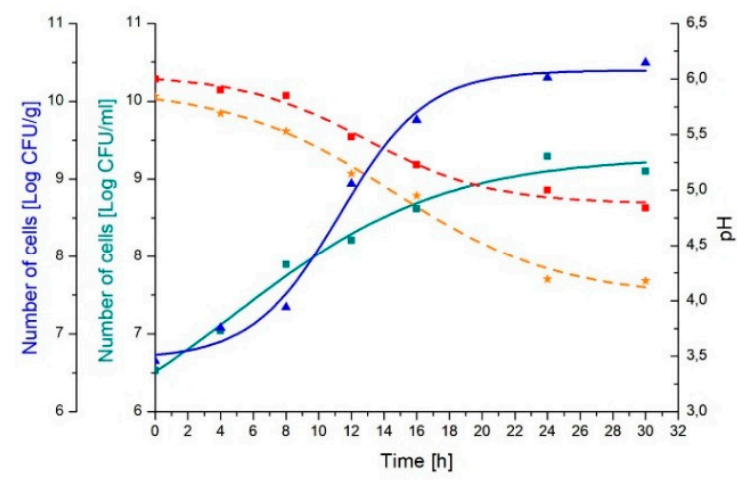

(c)

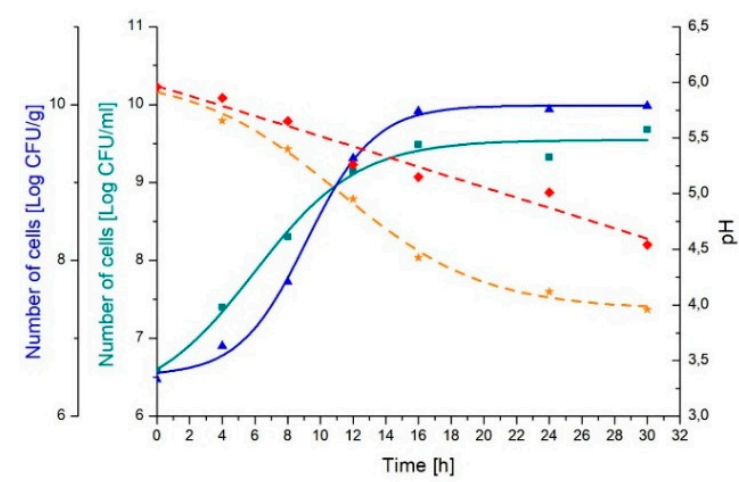

(e)

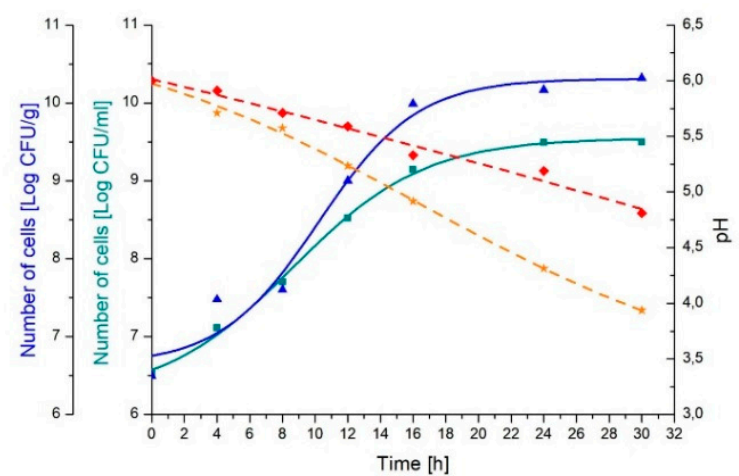

(b)

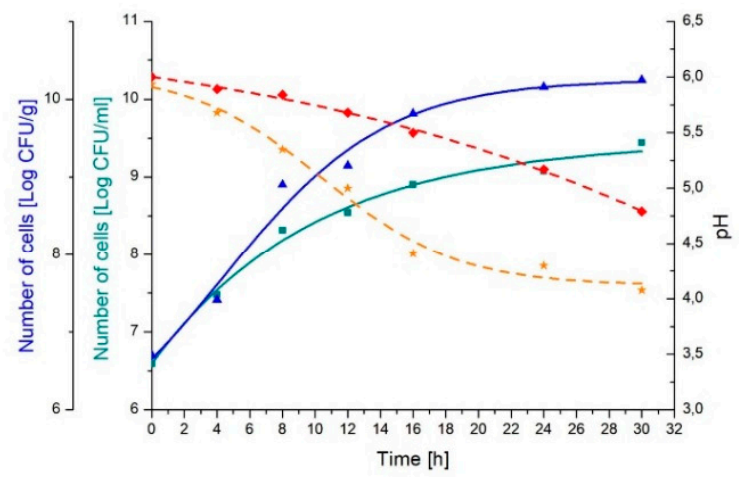

(d)

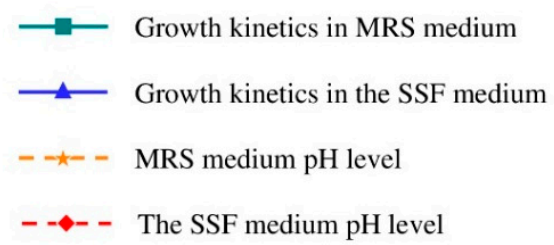

Figure 3. The growth kinetics of selected Lactobacillus spp., namely, Lb. rhamnousus ŁOCK 1087 (a), Lb. paracasei ŁOCK 1091 (b), Lb. reuteri ŁOCK 1092 (c), Lb. plantarum ŁOCK 0860 (d) and Lb. pentosus ŁOCK 1094 (e) cultivated in the semi-solid fermentation (SSF) medium or de Man, Rogosa, and Sharpe (MRS) broth, comparatively. Results are presented as the logarithm of colony-forming units per gram (Log CFU/g) or milliliter (Log CFU/mL).

Moreover, the cultivation of selected Lactobacillus spp. in the SSF medium resulted in up to two times higher maximum growth rate $\left(\mu_{\max }\right)$, which varied from 0.21 to $0.37 \mathrm{~h}^{-1}$, whereas $\mu_{\max }$ of bacteria grown in MRS medium did not exceed $0.23 \mathrm{~h}^{-1}$ (Table 3). Furthermore, the generation time (GT) was shorter when the SSF medium was used instead of MRS for the growth purposes varying from 0.96 to $1.41 \mathrm{~h}$ and 1.32 to $2.61 \mathrm{~h}$, respectively. Nevertheless, the tangible lag phase $(\lambda)$ was observed in the Lactobacillus strains cultures in the SSF medium reaching up to $5.64 \mathrm{~h}$, with exception of Lb. plantarum ŁOCK 0860 (Figure 3, Table 3). Contrary, a clear adaptation stage in the MRS medium was observed only when $L b$. paracasei ŁOCK 1091 was inoculated. 
Table 3. Growth parameters of selected Lactobacillus spp. probiotic strains cultivated in MRS and the SFF medium.

\begin{tabular}{ccccccc}
\hline \multirow{2}{*}{ Parameter $^{1}$} & \multicolumn{2}{c}{$\boldsymbol{\mu}_{\max }\left[\mathbf{h}^{\mathbf{- 1}}\right]$} & \multicolumn{2}{c}{$\lambda$ [h] } & \multicolumn{2}{c}{ GT [h] } \\
\cline { 2 - 7 } & MRS $^{\mathbf{2}}$ & SSF $^{\mathbf{3}}$ & MRS & SSF & MRS & SSF \\
\hline Lb. rhamnosus ŁOCK 1087 4,5 & 0.12 & 0.21 & - & 1.98 & 2.61 & 1.41 \\
Lb. paracasei ŁOCK 1091 & 0.18 & 0.27 & 1.14 & 4.04 & 1.65 & 1.10 \\
Lb. reuteri ŁOCK 1092 & 0.14 & 0.31 & - & 5.64 & 2.17 & 0.96 \\
Lb. plantarum ŁOCK 0860 & 0.15 & 0.22 & - & - & 2.06 & 1.37 \\
Lb. pentosus ŁOCK 1094 & 0.23 & 0.37 & - & 4.73 & 1.32 & 0.81 \\
\hline
\end{tabular}

${ }^{1}$ Analysed parameters: $\mu_{\max }$-maximum growth rate; $\lambda$-duration of the lag phase; GT-generation time; ${ }^{2}$ MRS is the abbreviation of de Man, Rogosa, and Sharpe broth; ${ }^{3}$ SSF stand for the semi-solid fermentation medium; ${ }^{4} L b$. is the abbreviation of Lactobacillus sp.; ${ }^{5}$ ŁOCK is a designation of strains obtained from the Lodz Collection of Pure Cultures (Institute of Fermentation Technology and Microbiology, Lodz University of Technology; Lodz, Poland).

\section{Discussion}

Cereals are mainly composed of carbohydrates, which constitute up to $75 \%$ of a grains dray mass; however, they are also a good source of proteins, whereas lipids are a minor part of their nutrients (1.7 to $7.0 \%$ of dry mass) [29]. Moreover, grains contain a considerable amount of vitamin $\mathrm{E}$ and ones belonging to the B-group as well as minerals such as zin, ion, magnesium, and calcium, which are necessary for Lactobacillus spp. growth $[29,30]$. Despite the substantial reduction of the nutritional value of cereals during the process of milling, which is defined as grinding grains into flour or meal, their bioavailability is increased [31]. On this basis, the flours were chosen as the main components of the SSF medium used for selected Lactobacillus strains in the following study.

Water activity and $\mathrm{pH}$ level of cultivation medium, as well as the temperature of incubation, are one of the most influential factors in terms of growth, viability, and activity of probiotic cultures [32]. It was established that the highest numbers of each Lactobacillus strain, up to $10^{10} \mathrm{CFU} / \mathrm{g}$, were obtained in the medium combining flour and water with a ratio of 1:1.5, respectively. Denkova and Krastnowa (2012) observed a slightly higher count of Lactobacillus spp., even up to $10^{11} \mathrm{CFU} / \mathrm{g}$, in the medium in which the ratio of wheat flour to water was $44 \%: 56 \%$ [33]. However, on the contrary to our research, analyzed Lactobacillus strains were isolated from the naturally fermented sourdough, which may result in their better ability to colonize the environment than strains, described in our paper, isolated from livestock's GIT or plant silage [34].

To the current day studies of flours fermentation by lactic acid bacteria were mostly focused on these microorganisms' impact on sourdough features and bread-making, rather than the cultivation of bacteria and optimal growth conditions. Therefore, outcomes obtained from this study could be compared only with data gathered by researchers who performed analysis in other cultivation media. Sánchez et al. (2019), who reviewed over 30 researches considering various Lactobacillus strains growth requirements and conditions, observed that the incubation temperature of these bacteria varied from 23 to $42^{\circ} \mathrm{C}$, whereas $\mathrm{pH}$ ranged between 5.2 to 6.9 , depending on the used fermentation media [35]. In the following research. growth of analyzed Lactobacillus strains was observed in a wide range of temperatures $\left(20-44{ }^{\circ} \mathrm{C}\right)$ in both studied media; however, the highest yields of cells were obtained when the strains were cultivated at $37^{\circ} \mathrm{C}$, which was in line with outcomes gathered by Lim (2010) [36]. Yang et al. (2018) also noted that the temperature of cultivation is influential in terms of Lactobacillus spp. growth and regardless of used medium, namely, MRS or Brain Heart Infusion broth (BHI), the highest bacteria population density was observed at $37^{\circ} \mathrm{C}$, which was in agreement with data presented in the following paper [37]. Furthermore, the analyzed Lactobacillus spp. also adapted well to the various initial $\mathrm{pH}$ levels, ranging from 4.0 to 6.5 , regardless of used media, which was in line with the results described by $\operatorname{Lim}$ (2010) [36]. In the SSF medium with $\mathrm{pH}$ value set at 6.0, all of the analyzed strains obtained the highest numbers of cells. The natural $\mathrm{pH}$ of used flours, namely, wheat, barley, maize, and rye, oscillates mostly around 6.0, and after they were mixed with water the SSF medium initial value was exactly 6.0 without any adjustments [38-40]. These indicate that there might 
not be needed substantial $\mathrm{pH}$ alterations in the SSF medium, which could reduce the costs of medium production. On the other hand, the impact of the initial $\mathrm{pH}$ of the MRS was strain-dependent and the optimal value ranged between 5.5 and 6.5 , which could raise the difficulty in adjusting the initial $\mathrm{pH}$ for the production of all strains. Juarez Tomás et al. (2002) noted, that the optimal initial pH for Lb. salivarius subsp. salivarius CRL 1328 was 6.5, despite used media, namely, MRS or LAPTg broths [41]. Meena et al. (2014), however, observed the growth of Lb. acidophilus NCDC 14 in MRS with initial $\mathrm{pH}$ ranging from approximately $3.0 \mathrm{up}$ to more than 7.0, whereas the optimal initial $\mathrm{pH}$ was 6.08. These differences in optimal initial $\mathrm{pH}$ levels, established by other research teams, underline the strain-dependency in growth performance in MRS broth regarding initial $\mathrm{pH}$, which was not observed for the SSF medium in the following research [42].

The growth kinetics analysis of each strain was performed in the previously determined optimal conditions of temperature $\left(37^{\circ} \mathrm{C}\right)$ and $\mathrm{pH}(6.0)$, in both MRS broth and the newly developed SSF medium. A substantially higher number of each Lactobacillus strain was observed in the SSF medium; however, on the contrary to the cultures conducted in MRS, strains monocultures, except Lb. plantarum ŁOCK 0860, exhibited unequivocal adaptation phase (lag phase), which average duration was $4.10 \pm 1.56 \mathrm{~h}$ in the alternative medium. Herrera-Ponce et al. (2014) observed comparable lag phase duration when monocultures of $\mathrm{Lb}$. casei $(431)$ and $\mathrm{Lb}$. acidophilus $\left(\mathrm{LA}-5^{\circledR}\right)$ were cultivated in a simple oat medium (oat flour mixed with tap water) [43]. Nevertheless, preadaptation of selected Lactobacillus strains to the SSF medium could result in a reduction of lag phase duration, since genetic changes might need to occur for strains to be able to adapt its metabolism and grow in the new media [17,44]. Despite the elongated lag phase, not only cell yields were increased but also up to more than two times higher growth rates were noted during the cultivation of analyzed strains in the SSF medium. These findings were in agreement with Brignone et al. (2017), whose research aimed to select a substance for Lactobacillus spp. growth enhancement [45]. Moreover, comparable growth rates, as one exhibited by Lb. rhamnosus ŁOCK $1087\left(0.21 \mathrm{~h}^{-1}\right)$ and Lb. plantarum ŁOCK $0860\left(0.22 \mathrm{~h}^{-1}\right)$, were observed by Saman et al. (2011), who analyzed $L b$. plantarum NCIMB 8826 growth in whole brown rice and rice bran broths [46]. The growth of the rest of the analyzed strains was faster, and its rate varied from 0.27 to $0.37 \mathrm{~h}^{-1}$, which was similar to the results obtained by Ruiz Rodríguez et al. (2019), who cultivated Lactobacillus spp. strains in formulated fruit simulation medium (FSM) [47]. These indicate the dependency of growth rate not only on medium composition but also on strains. Furthermore, the generation time was also in relation to strain and media used for its cultivation. The shortest doubling time was observed for $L b$. pentosus ŁOCK 1094, whereas the longest time to double the number of cells was needed for Lb. rhamnosus ŁOCK 1087, in both MRS broth and the SSF medium. Nevertheless, it was noted that the replacement of MRS broth with tested SSF medium resulted in up to over 2 times shorter generation time, which oscillated around $67.80 \pm 15.54 \mathrm{~min}$. Similar results were obtained by Bundinich et al. (2011), whose research team cultivated Lb paracasei ATCC 334 in cheese extract medium obtained from Cheddar cheese of different age; however, the final number of cells was significantly lower than observed in the following analysis [48]. In summary, the results of the performed growth kinetics analysis show a positive effect of the newly developed SSF medium usage, even despite the elongated lag phase.

The shift from the MRS broth to the SFF medium as the cultivation environment not only impacted the growth kinetics of selected Lactobacillus strains, but also the changes in media $\mathrm{pH}$ levels. The decrease of MRS broth $\mathrm{pH}$ values during incubation of selected strains monocultures was more considerable than observed in the SSF medium. The final average $\mathrm{pH}$ level of MRS broth was $4.04 \pm 0.10$, which was in line with the results described by Shokryazdan et al. (2015), whereas the SSF medium mean $\mathrm{pH}$, after $30 \mathrm{~h}$ of Lactobacillus spp. growth, was $4.75 \pm 0.12$ [49]. The end products of lactic acid bacteria fermentation, mainly organic acids, such as lactate or acetate, which are associated with the antimicrobial activity of strains, are responsible for the reduction of medium $\mathrm{pH}$ levels [50-52]. Zalán et al. (2010) previously observed that medium composition influences organic acids production [53]. Moreover, Śliżewska and Chlebicz-Wójcik (2020) noted significant variations in 
metabolic profiles of analyzed Lactobacillus spp., especially organic acids production, when strains were cultivated in MRS broth with different carbon source [54]. Therefore, one of the reasons for the limited reduction of the SSF medium $\mathrm{pH}$ could be decreased synthesis of organic acids caused by the form of carbon source, which is mainly starch that is less available for hydrolysis, than soluble glucose in MRS broth [53,55-57].

One of the research limitations was a lack of analysis of metabolites produced by Lactobacillus spp. in the SSF medium. This should be studied in the future for further confirmation of its applicability as the cost-efficient medium for these bacteria cultivation. Moreover, it could unambiguously justify differences in the $\mathrm{pH}$ reduction of the newly developed medium which could be caused by variations in the type and amount of produced metabolites. Furthermore, assays were performed on a limited number of strains that probiotic properties were recently described [24]. Despite, it was sufficient to draw conclusions, the impact of the SSF medium on the growth performance of other Lactobacillus strains should be further investigated.

\section{Conclusions}

The new cost-efficient medium was composed based on the commercial flours from cereals, such as wheat, barley, maize, and rye, mixed with distilled water. The preparation of the media would not bring additional costs, since the most substantial growth of selected Lactobacillus strains was supported in the media with unmodified $\mathrm{pH}(6.0)$ and in the temperature, which is most often applied during Lactobacillus spp. cultivation $\left(37^{\circ} \mathrm{C}\right)$. The growth kinetics indicates that adaptation of bacteria to a new medium is necessary; however, the growth of the strains is more efficient. Therefore, the newly developed semi-solid fermentation medium is a promising alternative for high cell density production of Lactobacillus spp.

Author Contributions: Conceptualization, K.Ś., and A.C.-W.; methodology, K.Ś.; formal analysis, A.C.-W.; investigation, A.C.-W.; resources, K.S.; data curation, A.C.-W.; writing—original draft preparation, A.C.-W., and K.Ś.; writing—review and editing, A.C.-W.; visualization, A.C.-W.; supervision, K.Ś.; project administration, K.Ś.; funding acquisition, K.Ś. All authors have read and agreed to the published version of the manuscript.

Funding: This research was funded by the National Centre for Research and Development, grant number PBS3/A8/32/2015.

Acknowledgments: We would like to thank the National Centre for Research and Development for the financial support of the research and publication of this paper as part of the project PBS3/A8/32/2015 realized within the framework of the Program of Applied Studies.

Conflicts of Interest: The authors declare no conflict of interest.

\section{References}

1. Alayande, K.A.; Aiyegoro, O.A.; Ateba, C.N. Probiotics in animal husbandry: Applicability and associated risk factors. Sustainability 2020, 12, 1087. [CrossRef]

2. Zoumpopoulou, G.; Kazou, M.; Alexandraki, V.; Angelopoulou, A.; Papadimitriou, K.; Pot, B.; Tsakalidou, E. Probiotics and prebiotics: An overview on recent trends. In Probiotics and Prebiotics in Animal Health and Food Safety; Di Gioia, D., Biavati, B., Eds.; Springer: Cham, Switzerland, 2018; pp. 1-34, ISBN 9783319719504.

3. Sharifi-Rad, J.; Rodrigues, C.F.; Stojanović-Radić, Z.; Dimitrijević, M.; Aleksić, A.; Neffe-Skocińska, K.; Zielińska, D.; Kołożyn-Krajewska, D.; Salehi, B.; Milton Prabu, S.; et al. Probiotics: Versatile bioactive components in promoting human health. Medicina 2020, 56, 433. [CrossRef] [PubMed]

4. Ciceero, A.F.G.; Fogacci, F.; Bove, M.; Giovannini, M.; Borgi, C. Impact of a short-term synbiotic supplementation on metabolic syndrome and systemic inflammation in elderly patients: A randomized placebo-controlled clinical trial. Eur. J. Nutr. 2020. [CrossRef] [PubMed]

5. Hernández, A.; Larsson, C.U.; Sawicki, R.; van Niel, E.W.J.; Roos, S.; Håkansson, S. Impact of the fermentation parameters $\mathrm{pH}$ and temperature on stress resilience of Lactobacillus reuteri DSM 17938. AMB Express 2019, 9, 66. [CrossRef] 
6. Dong, Z.; Gu, L.; Zhang, J.; Wang, M.; Du, G.; Chen, J.; Li, H. Optimisation for high cell density cultivation of Lactobacillus salivarius BBE 09-18 with response surface methodology. Int. Dairy J. 2014, 34, 230-236. [CrossRef]

7. Manzoor, A.; Qazi, J.I.; Haq, I.U.; Mukhtar, H.; Rasool, A. Significantly enhanced biomass production of a novel bio-therapeutic strain Lactobacillus plantarum (AS-14) by developing low cost media cultivation strategy. J. Biol. Eng. 2017, 11, 17. [CrossRef]

8. Wang, T.; Lu, Y.; Yan, H.; Li, X.; Wang, X.; Shan, Y.; Yi, Y.; Liu, B.; Zhou, Y.; Lü, X. Fermentation optimization and kinetic model for high cell density culture of a probiotic microorganism: Lactobacillus rhamnosus LS-8. Bioprocess Biosyst. Eng. 2020, 43, 515-528. [CrossRef]

9. Pallin, A.; Agback, P.; Jonsson, H.; Roos, S. Evaluation of growth, metabolism and production of potentially bioactive components during fermentation of barley with Lactobacillus reuteri. Food Microbiol. 2016, 57, 159-171. [CrossRef]

10. Ayad, A.; Gad El-Rab, D.; Ibrahim, S.; Williams, L. Nitrogen sources effect on Lactobacillus reuteri growth and performance cultivated in date palm (Phoenix dactylifera L.) by-products. Fermentation 2020, 6, 64. [CrossRef]

11. Hayek, S.A.; Gyawali, R.; Aljaloud, S.O.; Krastanov, A.; Ibrahim, S.A. Cultivation media for lactic acid bacteria used in dairy products. J. Dairy Res. 2019, 86, 490-520. [CrossRef]

12. Budhwar, S.; Sethi, K.; Chakraborty, M. Efficacy of germination and probiotic fermentation on underutilized cereal and millet grains. Food Prod. Process. Nutr. 2020, 2, 12. [CrossRef]

13. Davoodi, S.; Behbahani, M.; Shirani, E.; Mohabatkar, H. Influence of sucrose, glucose, stevia leaf and stevioside on the growth and lactic acid production by Lactobacillus plantarum, Lactobacillus brevis and Lactobacillus casei. Iran. J. Sci. Technol. Trans. A Sci. 2016, 40, 275-279. [CrossRef]

14. Dalcanton, F.; Carrasco, E.; Pérez-Rodríguez, F.; Posada-Izquierdo, G.D.; Falcão De Aragão, G.M.; García-Gimeno, R.M. Modeling the combined effects of temperature, $\mathrm{pH}$, and sodium chloride and sodium lactate concentrations on the growth rate of Lactobacillus plantarum ATCC 8014. J. Food Qual. 2018, 2018, 1726761. [CrossRef]

15. König, H.; Berkelmann-Löhnertz, B. Maintenance of wine-associated microorganisms. In Biology of Microorganisms on Grapes, in Must and in Wine; König, H., Gottfried, U., Fröhlich, J., Eds.; Springer: Cham, Switzerland, 2017; pp. 549-572, ISBN 9783319600215.

16. Zhou, K.; Zeng, Y.T.; Han, X.F.; Liu, S.L. Modelling Growth and Bacteriocin Production by Lactobacillus plantarum BC-25 in Response to Temperature and pH in Batch Fermentation. Appl. Biochem. Biotechnol. 2015, 176, 1627-1637. [CrossRef] [PubMed]

17. Bertranda, R.L. Lag phase is a dynamic, organized, adaptive, and evolvable period that prepares bacteria for cell division. J. Bacteriol. 2019, 201, e00697. [CrossRef]

18. Rezvani, F.; Ardestani, F.; Najafpour, G. Growth kinetic models of five species of Lactobacilli and lactose consumption in batch submerged culture. Braz. J. Microbiol. 2017, 48, 251-258. [CrossRef]

19. Śliżewska, K.; Motyl, I.; Libudzisz, Z.; Otlewska, A.; Burchardt, H.; Klecha, J.; Henzler, J. Lactobacillus plantarum Lactic Bacteria Strain. PL Patent 221959 B1, 30 June 2016.

20. Śliżewska, K.; Chlebicz, A. Lactic Bacterial Strain of Lactobacillus pentosus. PL Patent 233261 B1, 30 September 2019.

21. Śliżewska, K.; Chlebicz, A. Lactic Bacterial Strain of Lactobacillus paracasei. PL Patent 233262 B1, 30 September 2019.

22. Śliżewska, K.; Chlebicz, A. Lactic Bacterial Strain of Lactobacillus reuteri. PL Patent 233263 B1, 30 September 2019.

23. Śliżewska, K.; Chlebicz, A. Lactic Bacterial Strain of Lactobacillus rhamnosus. PL Patent 233582 B1, 29 November 2019.

24. Śliżewska, K.; Chlebicz-Wójcik, A.; Nowak, A. Probiotic properties of new Lactobacillus strains intended to be used as feed additives for monogastric animals. Probiotics Antimicrob. Proteins 2020, 1-17. [CrossRef]

25. Śliżewska, K.; Chlebicz, A. Synbiotics impact on dominant faecal microbiota and short-chain fatty acids production in sows. FEMS Microbiol. Lett. 2019, 366, fnz157. [CrossRef]

26. Śliżewska, K.; Markowiak, P.; Żbikowski, A.; Szeleszczuk, P. Effects of synbiotics on the gut microbiota, blood and rearing parameters of chickens. FEMS Microbiol. Lett. 2019, 366, fnz116. [CrossRef] 
27. Markowiak, P.; Śliżewska, K.; Nowak, A.; Chlebicz, A.; Żbikowski, A.; Pawłowski, K.; Szeleszczuk, P. Probiotic microorganisms detoxify ochratoxin A in both a chicken liver cell line and chickens. J. Sci. Food Agric. 2019, 99, 4309-4318. [CrossRef]

28. Ming, L.C.; Halim, M.; Rahim, R.A.; Wan, H.Y.; Ariff, A. Bin Strategies in fed-batch cultivation on the production performance of Lactobacillus salivarius I 24 viable cells. Food Sci. Biotechnol. 2016, 25, 1393-1398. [CrossRef] [PubMed]

29. Liptáková, D.; Matejčeková, Z.; Valík, L. Lactic acid bacteria and fermentation of cereals and pseudocereals. In Fermentation Processes; Jozala, A., Ed.; IntechOpen Limited: London, UK, 2017.

30. Jaramillo, L.; Santos, D.; Borges, E.; Dias, D.; Pereira, N. Low-cost effective culture medium optimization for d-lactic acid production by Lactobacillus coryniformis subsp. torquens under oxygen-deprived condition. Ann. Microbiol. 2018, 68, 547-555. [CrossRef]

31. Oghbaei, M.; Prakash, J. Effect of primary processing of cereals and legumes on its nutritional quality: A comprehensive review. Cogent Food Agric. 2016, 2, 1136015. [CrossRef]

32. Aspri, M.; Papademas, P.; Tsaltas, D. Review on non-dairy probiotics and their use in non-dairy based products. Fermentation 2020, 6, 30. [CrossRef]

33. Denkova, Z.; Krastanov, A. Development of new products: Probiotics and probiotic foods. In Probiotics; Rigobelo, E., Ed.; IntechOpen Limited: London, UK, 2012; ISBN 978-953-51-5324-5.

34. Cen, S.; Yin, R.; Mao, B.; Zhao, J.; Zhang, H.; Zhai, Q.; Chen, W. Comparative genomics shows niche-specific variations of Lactobacillus plantarum strains isolated from human, Drosophila melanogaster, vegetable and dairy sources. Food Biosci. 2020, 35, 100581. [CrossRef]

35. Sánchez, Ó.J.; Barragán, P.J.; Serna, L. Review of Lactobacillus in the food industry and their culture media. Rev. Colomb. Biotecnol. 2019, 21, 63-73. [CrossRef]

36. Lim, S.M. Cultural conditions and nutritional components affecting the growth and bacteriocin production of Lactobacillus plantarum KC21. Food Sci. Biotechnol. 2010, 19, 793-802. [CrossRef]

37. Yang, E.; Fan, L.; Yan, J.; Jiang, Y.; Doucette, C.; Fillmore, S.; Walker, B. Influence of culture media, pH and temperature on growth and bacteriocin production of bacteriocinogenic lactic acid bacteria. AMB Express 2018, 8, 10. [CrossRef]

38. Zeng, J.; Gao, H.; Li, G.; Zhao, X. Characteristics of corn flour fermented by some Lactobacillus species. In Proceedings of the Computing and Intelligent Systems; Wu, Y., Ed.; Springer: Berlin/Heidelberg, Germany, 2011; pp. 433-441.

39. Skrede, G.; Storebakken, T.; Skrede, A.; Sahlstrom, S.; Sorensen, M.; Shearer, K.D.; Slinde, E. Lactic acid fermentation of wheat and barley whole meal flours improves digestibility of nutrients and energy in Atlantic salmon (Salmo salar L.) diets. Aquaculture 2002, 210, 305-321. [CrossRef]

40. Mesías, M.; Morales, F. Effect of different flours on the formation of hydroxymethylfurfural, furfural, and dicarbonyl compounds in heated glucose/flour systems. Foods 2017, 6, 14. [CrossRef]

41. Juarez Tomás, M.S.; Bru, E.; Wiese, B.; De Ruiz Holgado, A.A.P.; Nader-Macías, M.E. Influence of pH, temperature and culture media on the growth and bacteriocin production by vaginal Lactobacillus salivarius CRL 1328. J. Appl. Microbiol. 2002, 93, 714-724. [CrossRef] [PubMed]

42. Meena, G.S.; Kumar, N.; Majumdar, G.C.; Banerjee, R.; Meena, P.K.; Yadav, V. Growth characteristics modeling of Lactobacillus acidophilus using RSM and ANN. Braz. Arch. Biol. Technol. 2014, 57, 15-22. [CrossRef]

43. Herrera-Ponce, A.; Nevárez-Morillón, G.; Ortega-Rívas, E.; Pérez-Vega, S.; Salmerón, I. Fermentation adaptability of three probiotic Lactobacillus strains to oat, germinated oat and malted oat substrates. Lett. Appl. Microbiol. 2014, 59, 449-456. [CrossRef] [PubMed]

44. Hamill, P.G.; Stevenson, A.; McMullan, P.E.; Williams, J.P.; Lewis, A.D.R.; Sudharsan, S.; Stevenson, K.E.; Farnsworth, K.D.; Khroustalyova, G.; Takemoto, J.Y.; et al. Microbial lag phase can be indicative of, or independent from, cellular stress. Sci. Rep. 2020, 10, 5948. [CrossRef]

45. Brignone, D.; Radmann, P.; Behr, J.; Vogel, R.F. Boosting the growth of the probiotic strain Lactobacillus paracasei ssp. paracasei F19. Arch. Microbiol. 2017, 199, 853-862. [CrossRef] [PubMed]

46. Saman, P.; Fuciños, P.; Vázquez, J.A.; Pandiella, S.S. Fermentability of brown rice and rice bran for growth of human Lactobacillus plantarum NCIMB 8826. Food Technol. Biotechnol. 2011, 49, 128-132.

47. Ruiz Rodríguez, L.G.; Mohamed, F.; Bleckwedel, J.; Medina, R.; De Vuyst, L.; Hebert, E.M.; Mozzi, F. Diversity and functional properties of lactic acid bacteria isolated from wild fruits and flowers present in northern Argentina. Front. Microbiol. 2019, 10, 1091. [CrossRef] 
48. Budinich, M.F.; Perez-Díaz, I.; Cai, H.; Rankin, S.A.; Broadbent, J.R.; Steele, J.L. Growth of Lactobacillus paracasei ATCC 334 in a cheese model system: A biochemical approach. J. Dairy Sci. 2011, 94, 5263-5277. [CrossRef]

49. Shokryazdan, P.; Liang, J.B.; Abdullah, N.; Jahromi, M.F. Probiotic potential of lactic acid bacteria isolated from mulberry silage. J. Pure Appl. Microbiol. 2015, 9, 443-452.

50. Mora-Villalobos, J.A.; Montero-Zamora, J.; Barboza, N.; Rojas-Garbanzo, C.; Usaga, J.; Redondo-Solano, M.; Schroedter, L.; Olszewska-Widdrat, A.; López-Gómez, J.P. Multi-product lactic acid bacteria fermentations: A review. Fermentation 2020, 6, 23. [CrossRef]

51. Li, W.; Zhang, Y.; Li, H.; Zhang, C.; Zhang, J.; Uddin, J.; Liu, X. Effect of soybean oligopeptide on the growth and metabolism of Lactobacillus acidophilus JCM 1132. RSC Adv. 2020, 10, 16737-16748. [CrossRef]

52. Narendranath, N.V.; Power, R. Relationship between $\mathrm{pH}$ and Medium Dissolved Solids in Terms of Growth and Metabolism of Lactobacilli and Saccharomyces cerevisiae during Ethanol Production. Appl. Environ. Microbiol. 2005, 71, 2239-2243. [CrossRef] [PubMed]

53. Zalán, Z.; Hudáček, J.; Štětina, J. Production of organic acids by Lactobacillus strains in three different media. Eur. Food Res. Technol. 2010, 230, 395. [CrossRef]

54. Śliżewska, K.; Chlebicz-Wójcik, A. The In Vitro Analysis of Prebiotics to Be Used as a Component of a Synbiotic Preparation. Nutrients 2020, 12, 1272. [CrossRef]

55. Giraud, E.; Champaillier, A.; Raimbault, M. Degradation of Raw Starch by a Wild Amylolytic Strain of Lact. Plantarum. Appl. Environ. Microbiol. 1994, 60, 4319-4323. [CrossRef]

56. Majzoobie, M.; Farahnaksy, A.; Amiri, S. Physicochemical characteristics of starch component of wheat flours obtained from fourteen iranian wheat cultivars. Int. J. Food Prop. 2011, 14, 685-696. [CrossRef]

57. Hussein, A.M.S.; Kamil, M.M.; Hegazy, N.A.; El-Nor, S.A.H.A. Effect of wheat flour supplemented with barely and/or corn flour on balady bread quality. Pol. J. Food Nutr. Sci. 2013, 63, 11-18. [CrossRef]

Publisher's Note: MDPI stays neutral with regard to jurisdictional claims in published maps and institutional affiliations. 